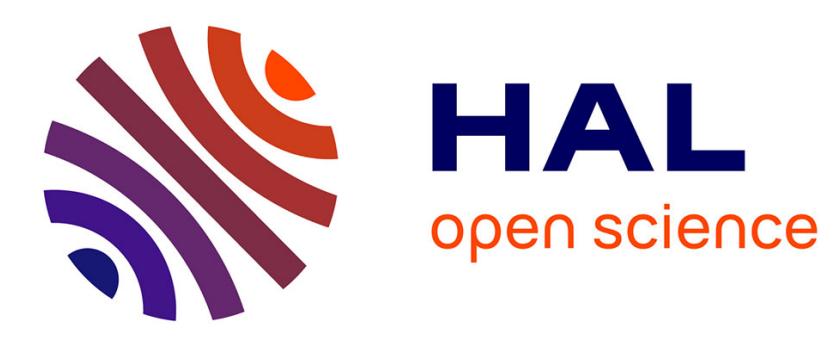

\title{
Wake numerical study of a vertical marine current turbine
}

Mathilde Belhache, Sylvain Guillou, Philippe Grangeret, Dominique Mouazé, Alina Santa-cruz

\section{- To cite this version:}

Mathilde Belhache, Sylvain Guillou, Philippe Grangeret, Dominique Mouazé, Alina Santa-cruz. Wake numerical study of a vertical marine current turbine. La Houille Blanche - Revue internationale de l'eau, 2014, 6 (6), pp.74-78. 10.1051/lhb/2014066 . hal-01702034

\section{HAL Id: hal-01702034 \\ https://hal.science/hal-01702034}

Submitted on 6 Feb 2018

HAL is a multi-disciplinary open access archive for the deposit and dissemination of scientific research documents, whether they are published or not. The documents may come from teaching and research institutions in France or abroad, or from public or private research centers.
L'archive ouverte pluridisciplinaire HAL, est destinée au dépôt et à la diffusion de documents scientifiques de niveau recherche, publiés ou non, émanant des établissements d'enseignement et de recherche français ou étrangers, des laboratoires publics ou privés. 


\title{
Wake numerical study of a vertical marine current turbine
}

\author{
Mathilde BELHACHE', Sylvain GUILLOU ${ }^{1}$, Philippe GRANGERET ${ }^{1}$, \\ Dominique MOUAZÉ2, Alina SANTA-CRUZ ${ }^{1}$
}

\author{
1. Laboratoire Universitaire des Sciences Appliquées de Cherbourg (EA4253), Université de Caen, Site Universitaire de Cherbourg, BP78, \\ 50130 Cherbourg-Octeville. France. \\ mathilde.belhache@unicaen.fr,sylvain.guillou@unicaen.fr \\ 2. Laboratoire de Morphodynamique Continentale et Côtière (M2C), UMR CNRS 6143, 24 rue des tilleuls, 14000 Caen. France.
}

\begin{abstract}
The commercial exploitation of kinetic energy from tidal current involves deploying multiple turbines constituting a park or a farm. The turbines located within the park suffer from the disrupted flow due to the wake of machines located further upstream. This will potentially alter their performance. The evolution of the wake is influenced by the environment and by the machine. A two-dimensional model of a vertical axis turbine of Darrieus type was performed to investigate the flow within and downstream the turbine. The relative influences on the characteristics of the wake of two parameters were evaluated: the speed of the upstream flow and the Tip speed ratio $\lambda$. The latter seems to be dominant for the lack of speed while the level of turbulence is a function of the two parameters setting.
\end{abstract}

Key-words: Marine Renewable Energy, Vertical axis current turbine, numerical simulation, wake, turbulence, Marine current turbine farm.

\section{Etude numérique du sillage d'une hydrolienne à axe vertical}

\begin{abstract}
RÉSUMÉ. - L'exploitation de l'énergie cinétique des courants de marée impliquera le déploiement de plusieurs hydroliennes constituant un parc. Les hydroliennes se trouvant au sein de ce parc subiront le flux perturbé du sillage des machines situées plus en amont, altérant potentiellement leurs performances. L'évolution du sillage est influencée par l'environnement et la machine. Une modélisation bidimensionnelle d'une hydrolienne à axe verticale de type Darrieus a été réalisée pour étudier l'écoulement dans et en aval de la turbine. L'influence relative sur les caractéristiques du sillage de deux paramètres a été évaluée : la vitesse de l'écoulement amont et la vitesse réduite de l'hydrolienne. La vitesse réduite $\lambda$ semble être le paramètre dominant pour le déficit de vitesse alors que le niveau de turbulence est une fonction des deux paramètres.
\end{abstract}

Mots-clés : Energies Marines Renouvelables, Hydroliennes à axe vertical, simulation numérique, sillage, turbulence, ferme hydrolienne.

\section{INTRODUCTION}

The establishment of Tidal Energy Converter (TEC) involves interactions between the machines like the wake effects which could disrupt their behaviour. The evolution of the wake is influenced by two types of parameters, the environmental and the operating parameters. The former are associated with the hydrodynamic of the installation site, and in particular with the turbulence level. It depends on the fluid velocity, the bathymetric variations, the nature of the sea bed and its roughness, the effect of the free surface, and the position of the machine in the water column.

The seconds are those that determine the behaviour of the machine, that is to say, the parameters that define at which tip speed ratio $\lambda$ (Equation 1) the turbine will work for a given current speed. The tip speed ratio is the ratio between the speed of the blades (due to the rotation) and the upstream fluid velocity (where $\mathrm{R}$ is the radius of the turbine $(\mathrm{m}), \omega$ is the angular velocity (rad.s $\left.{ }^{-1}\right)$ and $U_{0}$ is the upstream flow velocity $\left(\mathrm{m} \cdot \mathrm{s}^{-1}\right)$ ).

$$
\lambda=\mathrm{R} \omega / \mathrm{U}_{0}
$$

This tip speed ratio (Fig. 1) depends on the design of the mechanical system but also on the power conversion system to which the turbine is coupled. For a given flow velocity the machine is more or less effective in extracting energy according to its rotational speed (characteristic of the mechanical system). There is an optimum rotational speed. The operating point $(\lambda)$ is determined by the interaction between the load torque imposed by the electric generator and the mechanical torque produced by the fan. It is essential to know the characteristics of the complete system as each operating point corresponds to a different flow regime that will generate different structures in the wake.

This study is designed to model and characterize the near wake (velocity, turbulence level) downstream of a tidal turbine in different operating conditions. The study is conducted on a Darrieus vertical axis tidal turbine which could be used in rotary currents and which would be little affected by turbulence (Ferreira, 2009). 


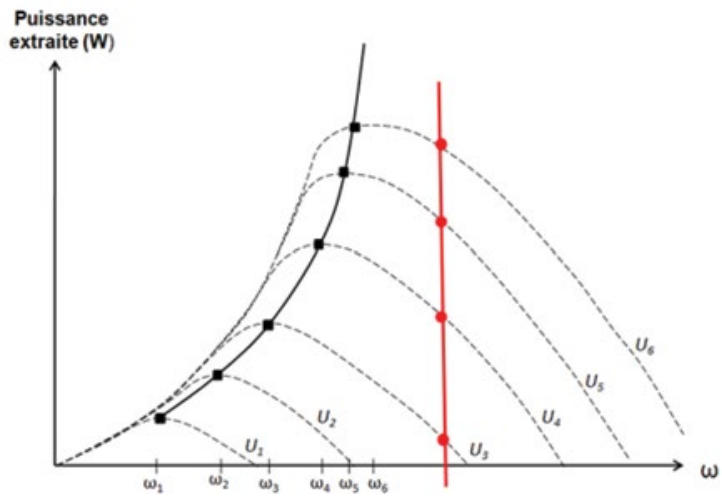

Figure 1: Schematic representation of the evolution of the power related to the rotational speed $(\omega 1, \omega 2, \omega 3 \ldots)$ for different upstream velocities (U1, U2, U3 ...). The red curve reflects the operation of a generator at constant speed rotation. The black curve is the one equipped with a system researching the maximum power.

\section{METHOD}

The characterization of the wake is very complex due to the large number of factors which are involved and vary independently in time and space. So at first glance, a number of simplifications are necessary. In this work, we propose a description of the wake downstream of a vertical axis tidal turbine by a two-dimensional model. Only the parameters related to the machine are considered here, the effect of the environmental turbulence is not investigated.

The URANS modelling were performed with the commercial code Ansys Fluent (v.14). The turbulent model used is the model k - $\omega$ SST (Shear Stress Transport Model). This strategy is more robust and more precise than standard Reynolds averaged models (URANS) for the airfoil geometries such as those used for the blades of turbines and can simulate the turbulence close to the wall, the one in the near wake and far wake (Vermeer et al. 2003).

\section{II.1. Parameters of the study}

Simulations were conducted for three velocities to reflect changes in the tidal currents. For each speed, four operating points have been tested for tip speeds ratio $(\lambda)$ between 2 and 5 . On all of these 12 cases, the rotation speed of the machine is imposed as model input and remains constant during the rotation (table 1).

\section{II.2. Validation}

The most commonly used Reynolds number to describe the flow within a vertical axis tidal turbine is the blade Reynolds number. It is based on the blade chord length (c) and on the blade velocity $(\mathrm{R} \omega)$. This number is constant along the rotation. Nevertheless, the flow within a Darrieus rotor is complex as it can be seen figure $2(\lambda=2)$. There are regions where the boundary layer remains attached to the blade, areas where stall regimes appear and regions where the blade interacts with its own wake at the same time. Thus for a given instant, each blade undergoes a completely different flow. So the blade Reynolds number is not anymore sufficient to characterize the flow around a blade during its rotation. Therefore, we prefer to use the Reynolds number $\operatorname{Re}_{c}^{\prime}=W c / v$ based on the relative velocity $\mathrm{W}$ perceived by the blades ( $v$ : fluid kinematic viscosity). The latter is estimated with the relationship ( $\theta$ : Azimuthal position of the blade): $W=U_{0} \sqrt{1+2 \lambda \sin \theta+\lambda^{2}}$. The calculated values for all the cases are between $8.10^{5}$ and $1.10^{7}$.

The model parameters and the boundary layer mesh were defined from static simulations performed on a single blade (NACA0012) for different attack angles. The drag and lift coefficients obtained on this range of Reynolds numbers were compared to experimental works conducted in a wind tunnel at the Sandia National Laboratory (Sheldahl \& Klimas, 1981). Drag coefficients calculated

Table 1: Rotational speeds imposed on the tidal turbine for each operating point $(\lambda)$ depending on the upstream fluid speed $\left(U_{0}\right)$.

\begin{tabular}{|l|c|c|c|c|}
\cline { 2 - 5 } \multicolumn{1}{c|}{} & \multicolumn{4}{c|}{$\lambda$} \\
\hline $\mathrm{U}_{0}$ & 2 & 3 & 4 & 5 \\
\hline $2 \mathrm{~m} . \mathrm{s}^{-1}$ & 1.33 & 2 & 2.66 & 3.33 \\
\hline $3 \mathrm{~m} . \mathrm{s}^{-1}$ & 2 & 3 & 4 & 5 \\
\hline $4.5 \mathrm{~m} . \mathrm{s}^{-1}$ & 3 & 4.5 & 6 & 7.5 \\
\hline
\end{tabular}

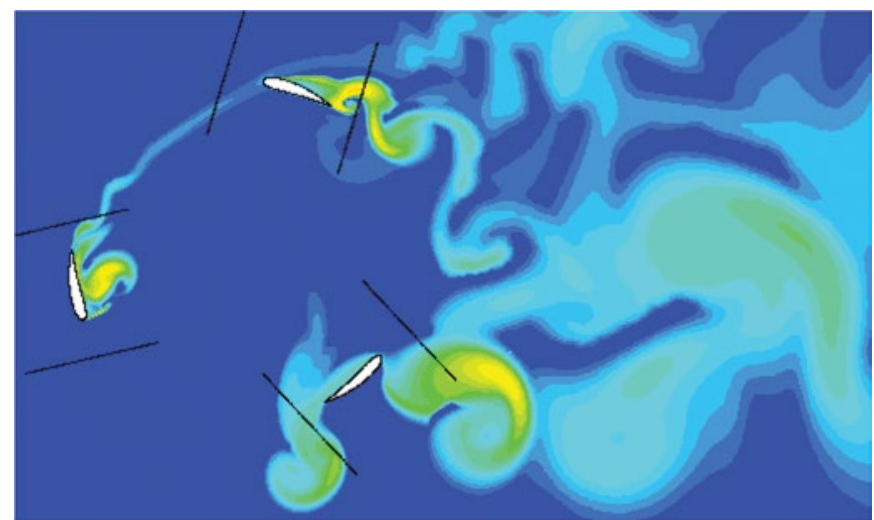

Figure 2: Details of the flow (turbulent intensity) within a Darrieus type turbine in regime of stall $(\lambda=2)$. 

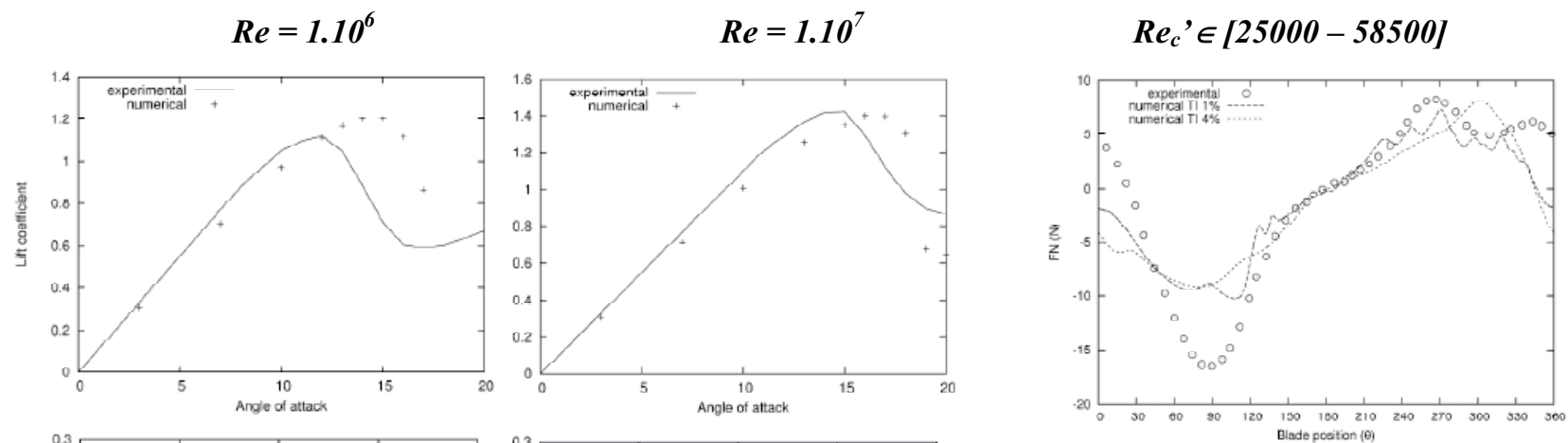

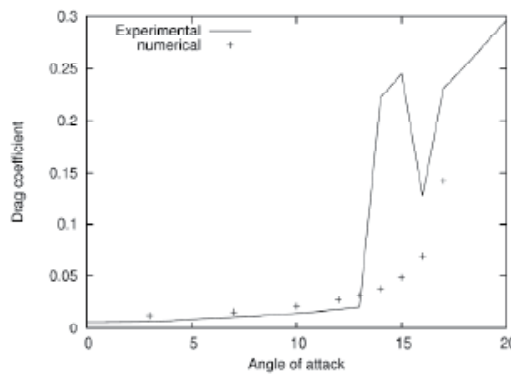

A

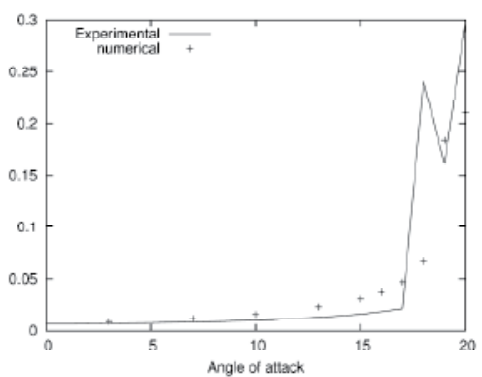

B

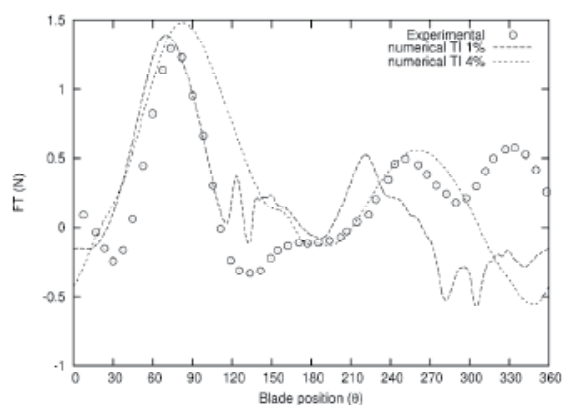

$\mathrm{C}$

Figure 3: A - B: lift and drag coefficients on a static blade in air flow for various Reynolds numbers (experiment from Sheldahl and klimas, 1981). C: Normal (FN) and tangential (FT) forces on a dynamic two-bladed turbine (experiment from Strickland et al. 1981).

by the model are rather good for both configurations (figure $3 \mathrm{~A}$ and $\mathrm{B}$ ). The lift coefficient behaviour is well described before the stall regime. The prediction of the stall transition is better as the Reynolds number increases. A dynamic validation was also conducted relatively to the experience carried out by Strickland and his team in 1981 on a two-bladed tidal turbine prototype in dynamic situation in a traction basin (figure $3 \mathrm{c}$ ). As the inlet turbulence intensity was not specified in the experiment, two cases, $1 \%$ and $4 \%$ rates were simulated. The magnitudes of computed tangential and normal forces are good and the trend is rather well reproduced for the normal force. The differences are mainly related to the three-dimensional effects and free surface effects which are not reproduced in the two-dimensional simulation.

\section{II.3. Characteristics of the computational domain}

From the static validation case a boundary layer $\mathrm{C}$ mesh, made of 81000 cells, was defined for each blade. The domain was covered with a non-structured grid of 690,000 elements where the finer cells have been located into the rotor and downstream of the machine so as to capture the detail of the flow in the wake (figure 4). The field extends over 6 rotor diameters $(6 \mathrm{D})$ upstream and $15 \mathrm{D}$ downstream of the machine. The channel is $6 \mathrm{D}$ width (which corresponds to a blockage ratio of 0.16 ). The domain is divided into two parts: a fixed one and a moving domain encompassing the turbine and allowing the rotation (sliding mesh). The two sub-domains are separated by a slippery interface (figure 4). Only the blades were represented in this $2 \mathrm{D}$ case (no mast
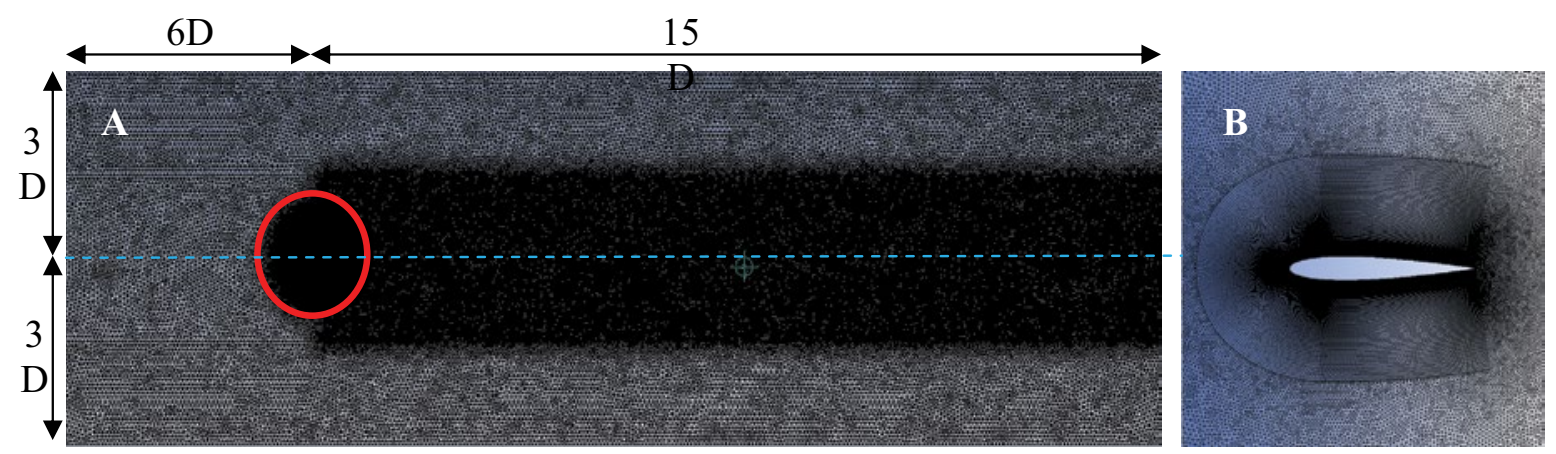

Figure 4: Computational domain and mesh. The dimensions are expressed in turbine diameter. The red circle represents the position of the sliding interface. Complete mesh (A) and detail of the C-boundary layer mesh around a blade (B). 
or arms). The blades are supposed to be of infinite length which will result in an underestimation of the drag particularly at the tips.

\section{RESULTS}

The twelve simulations carried out assess four flow regimes $(\lambda=2$ to $\lambda=5)$ in three upstream velocities $(2,3$ and $\left.4.5 \mathrm{~m} \cdot \mathrm{s}^{-1}\right)$. Each simulation is performed for 8 revolutions ensuring the stabilization of the flow in the near wake ( 2 or 3 diameters of turbine downstream of the machine).

\section{III.1. Turbulent intensity}

Figure 5.A shows the turbulence level in the wake of the tidal turbine for an upstream velocity of $3 \mathrm{~m} \cdot \mathrm{s}^{-1}$ related to the tip speed ratio $(\lambda)$. Note that the largest turbulent intensity generated at the level of the rotor corresponds to $\lambda=2$. This strong turbulent intensity is produced by the releases of vortex which are characteristic of low values of $\lambda$. This turbulence is asymmetrical relatively to the channel axis. As the tidal turbine increases in speed $(\lambda=3$ to $\lambda=5)$, the dynamics of the flow changes, the stalls disappear, and as a result the turbulent intensity created in the rotor is smaller and will be dissipated more quickly. This behaviour was also observed for the two other current velocities considered. Thus for a given flow velocity the wake will be more turbulent for small $\lambda$. For a constant value of $\lambda$, the turbulent level increases with the upstream fluid velocity (fig. 5.B). These results suggest that the dissipation of the turbulent wake will intervene further downstream for small values of $\lambda$ and when the current will increase. A longer calculation (until stabilisation of the far wake) will certainly verify these assumptions and will complete these preliminary results.

\section{III.2. Velocity deficit}

The same observation may be made by considering the velocity deficit in the wake. For a given current velocity (figure 6a), the flow dynamic is controlled by the value of $\lambda$. The higher is the $\lambda$ the more important is the velocity deficit in the near wake. Thus, for $\lambda=2$, the minimum velocity level in the wake represents about $50 \%$ of the energy contained in the upstream flow while for $\lambda=5$, it is only $15 \%$. When the rotation speed increases, a part of the flow bypasses the machine which explains why the deficit increases in the near wake with high values of $\lambda$. This phenomenon is visible in figure 6(a), where a deceleration of the fluid occurs upstream of the machine and which is more overt when the rotational speed increases.

For a given value of $\lambda$ (figure $6 \mathrm{~B}$ ), as for turbulence, we can see that the velocity of the flow can alter somewhat the importance of the velocity deficit but not drastically. Therefore, the parameter that controls the amount of energy available in the near wake is mainly the tip speed ratio $\lambda$.

\section{CONCLUSION AND OUTLOOK}

A modeling of a vertical axis tidal turbine of Darrieus type was carried out to investigate the flow in and downstream of the turbine. The relative influence of two parameters on the characteristics of the near wake was evaluated: the upstream flow velocity and the tip speed ratio of the turbine. It appears that the velocity deficit is mainly driven by the tip speed ratio. On the other hand, the importance of turbulence is an inverse function of the value of $\lambda$, and an increasing function of the upstream velocity. Additional long simulations must be performed to study the far wake.

However this preliminary study emphasis the importance to well know the complete turbine behaviour (mechanical system coupled with the electric system) to identify the operating points of the machine. It should be supplemented by a $3 \mathrm{D}$ study, as well as an investigation of the influence of the upstream turbulence. Taking into account explicitly the generator through the resistant torque is expected to increase the degree of realism of the model (Belhache et al., 2013). Finally, in order to consolidate this study, measurements in an experimental channel (force, velocity) are carried on a tidal turbine prototype.
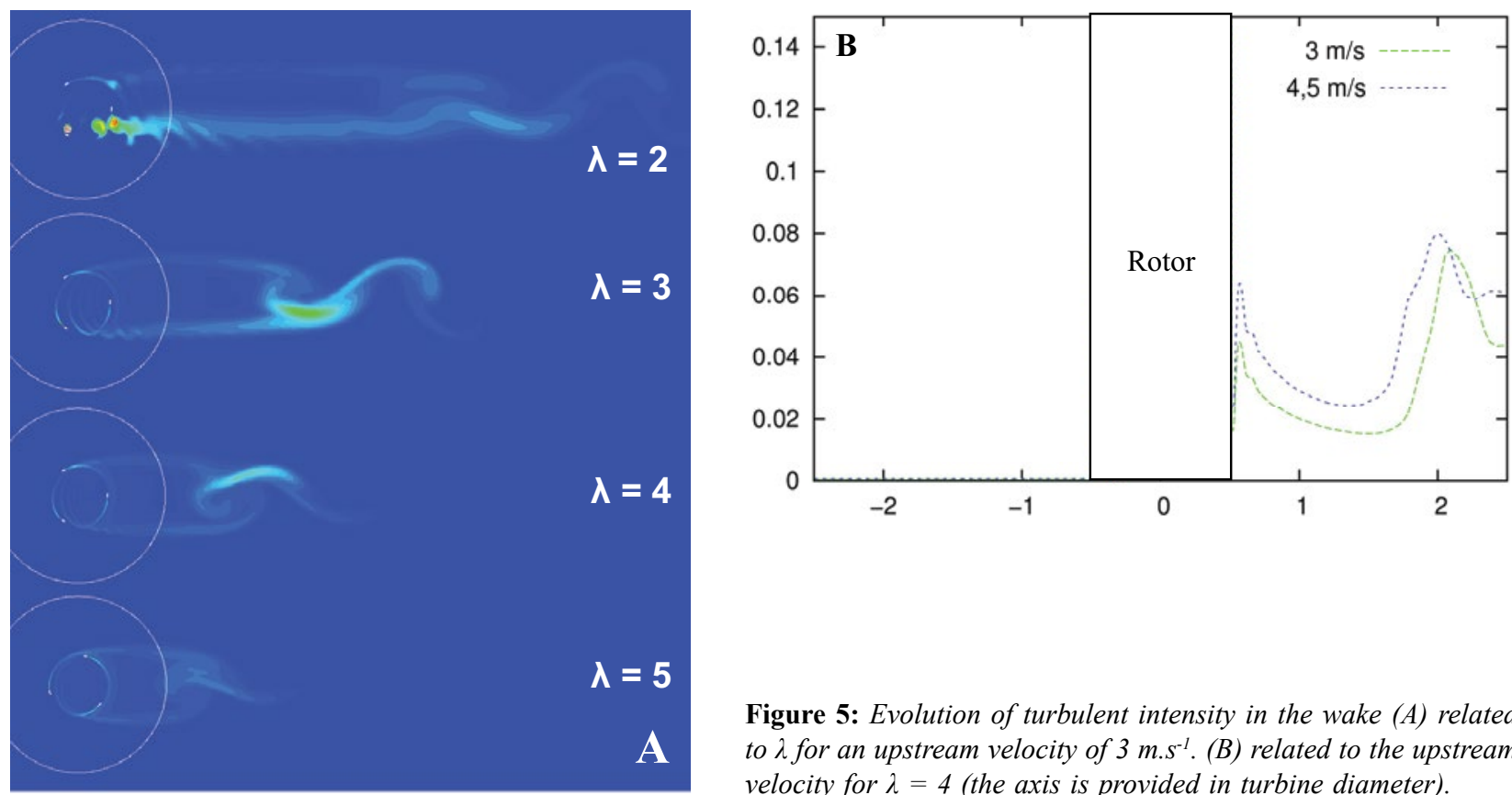

Figure 5: Evolution of turbulent intensity in the wake (A) related to $\lambda$ for an upstream velocity of $3 \mathrm{~m} . \mathrm{s}^{-1}$. (B) related to the upstream velocity for $\lambda=4$ (the axis is provided in turbine diameter). 

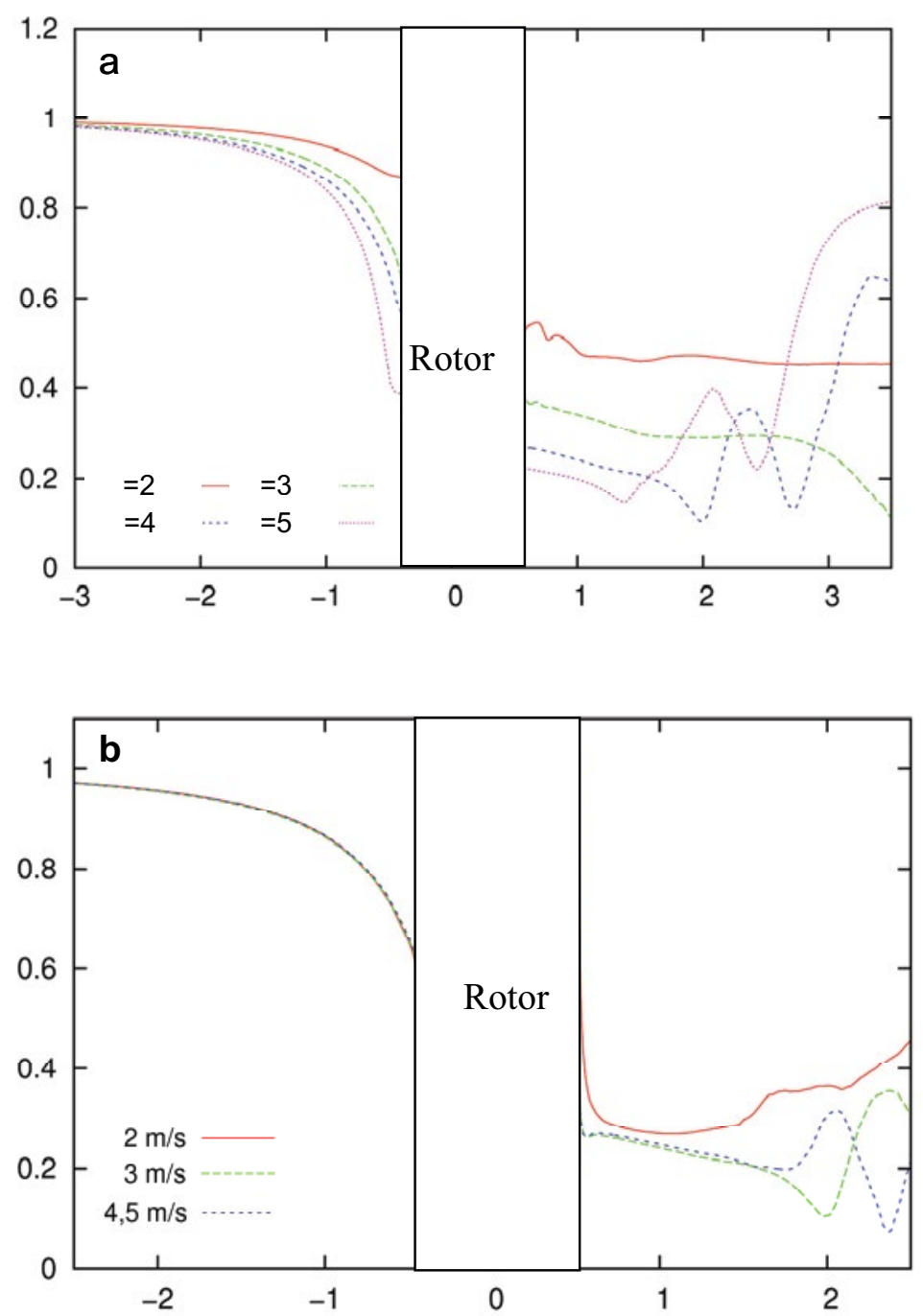

Figure 6: Non-dimensional velocity $u / U_{0}$ along the channel axis (the unit is the turbine diameter) near the turbine: a) $U_{0}=3 m \cdot s^{-1}$; b) $\lambda=4$.

\section{ACKNOWLEDGEMENT}

This study was founded in association by the Low Normandy region and the society WIBEE (Wind Building Engineering). We would like to thank the Syndicat Mixte du Cotentin for financing the computational resources.

\section{RÉFÉRENCES}

Belhache M., Guillou S., Grangeret P., M. Santa-Cruz A., Bellanger F. (2013) - Fluid Structure Interaction Of A Loaded Darrieus Marine Current Turbine. Renewable Energy And Power Quality Journal (Re\&Pqj). 11
FERREIRA C.S. (2009) - The near wake of the VAWT- $2 D$ and $3 D$ views of the VAWT aerodynamics, Thèse de doctorat de l'Université de Technologie de Delft. 279

Sheldahl R.E. Et Klimas P.C. (1981) - Aerodynamic characteristics of seven symmetrical airfoil sections through 180-degree. Angle of attack for use in aerodynamic analysis of vertical axis wind turbines, Sandia National Laboratories

Strickland J.H., Smith T., Sun K. (1981) - A vortex Model of the Darrieus Turbine: An analytical and Experimental Study, Sandia National Laboratories, Albuquerque, NM, SAND81-7017

Vermeer L.J., Sørensen J.N. Et Cespo A. (2003) - Wind turbine wake aerodynamics. Progress in Aerospace Sciences. 39 : 467-510 